\title{
Investigation of the neural risk factors for postoperative delirium using magnetic resonance imaging
}

\author{
Jung Eun Shin, $\mathrm{PhD}^{1}$, Chanyoung Ko, MD², Sunghyon Kyeong, $\mathrm{PhD}^{1}$, Kyu Hyun Yang, \\ $\mathrm{MD}, \mathrm{PhD}^{3}$, Woo Suk Lee, MD³ , Tae-Sub Chung, MD, PhD4, Jae-Jin Kim, MD, PhD ${ }^{1,2}$ \\ 1 Institute of Behavioral Science in Medicine, Yonsei University College of Medicine, Seoul, Korea \\ 2 Department of Psychiatry, Yonsei University College of Medicine, Seoul, Korea \\ ${ }^{3}$ Department of Orthopedic Surgery, Yonsei University College of Medicine, Seoul, Korea \\ ${ }^{4}$ Department of Radiology, Yonsei University College of Medicine, Seoul, Korea
}

Objectives: Delirium is an acute confusional state that is characterized by sudden alteration and fluctuation in consciousness and cognition associated with impaired attention. Delirium frequently occurs after surgery, particularly in patients undergoing hip fracture, however, the underlying neural mechanism remains uncertain. The present study aimed to investigate predictive neural correlates of postoperative delirium.

Methods: Before surgery, patients with hip fracture were assessed for cognitive impairment and scanned using magnetic resonance imaging. After surgery, they were evaluated for postoperative delirium for 7 successive days and additional functional scans were performed on postoperative delirium onset or the end of assessment day according to postoperative delirium occurrence. Then anatomical and functional data were analyzed with voxel based morphometry, diffusion tensor imaging, and functional connectivity analysis.

Results: Patients with postoperative delirium, compared with patients without postoperative delirium, showed decreased gray matter (GM) volume in the medial prefrontal cortex, precuneus, superior and transverse temporal gyri, and caudate nucleus. In functional connectivity, patients with postoperative delirium showed increased connectivity between the medial prefrontal cortex and precuneus and between the transverse temporal gyrus and precentral gyrus, and decreased connectivity between the superior temporal gyrus and superior frontal gyrus and between the transverse temporal gyrus and middle occipital gyrus.

Comparison of preoperative functional connectivity with each seed between patients with and without postoperative delirium

\begin{tabular}{|c|c|c|c|c|c|c|c|}
\hline \multirow{2}{*}{ Seed } & \multirow{2}{*}{ Comparison } & \multirow{2}{*}{$\begin{array}{l}\text { Brain region } \\
\text { (Brodmann area) }\end{array}$} & \multirow{2}{*}{ Nvox } & \multirow{2}{*}{$Z \max$} & \multicolumn{3}{|c|}{ 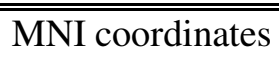 } \\
\hline & & & & & $\mathrm{x}$ & $\mathrm{y}$ & $\mathrm{z}$ \\
\hline $\begin{array}{l}\text { Supplementary } \\
\text { motor area }\end{array}$ & $\begin{array}{l}\text { Delirium } \\
>\text { Non-delirium }\end{array}$ & $\begin{array}{l}\text { R. Lateral occipital } \\
\text { gyrus (19) }\end{array}$ & 56 & 3.89 & 18 & -83 & 45 \\
\hline Temporal pole & $\begin{array}{l}\text { Delirium } \\
<\text { Non-delirium }\end{array}$ & $\begin{array}{l}\text { R. Middle frontal } \\
\text { gyrus (9) }\end{array}$ & 54 & 3.86 & 28 & 28 & 50 \\
\hline \multirow[t]{2}{*}{$\begin{array}{l}\text { Transverse } \\
\text { temporal gyrus }\end{array}$} & $\begin{array}{l}\text { Delirium } \\
<\text { Non-delirium }\end{array}$ & $\begin{array}{l}\text { L. Lateral occipital } \\
\text { gyrus (19) }\end{array}$ & 60 & 4.15 & -28 & -89 & 17 \\
\hline & $\begin{array}{l}\text { Delirium } \\
\text { > Non-delirium }\end{array}$ & $\begin{array}{l}\text { L. Precentral gyrus } \\
\text { (6) }\end{array}$ & 54 & -3.71 & -24 & -15 & 75 \\
\hline
\end{tabular}

$L$, left; $R$, right; Nvox, the number of voxel; Zmax, $X$ maximum within a cluster; MNI, Montreal Neurological Institute Age, gender, gray matter volume, and mini-mental state examination scores were used as covariates.
Conclusion: GM density in the caudate/suprachiasmatic nucleus was suggested be an important neural predisposing factor for postoperative delirium in a previous study. To exclude the involvement of dementia in postoperative delirium occurrence, scores for cognitive impairments were used as covariate on voxel based morphometry. Based on this study, brain regions other than the caudate nucleus were identified that may predispose individuals to develop delirium appear to be the supplementary motor area, precuneus, temporal pole, transverse temporal gyrus, and the superior temporal gyrus. Furthermore, two sets of brain regions showed increased functional connectivity-one connectivity may be associated with improved capacity to recover from pathological mental state and the other may be associated with greater vulnerability to develop delirium.

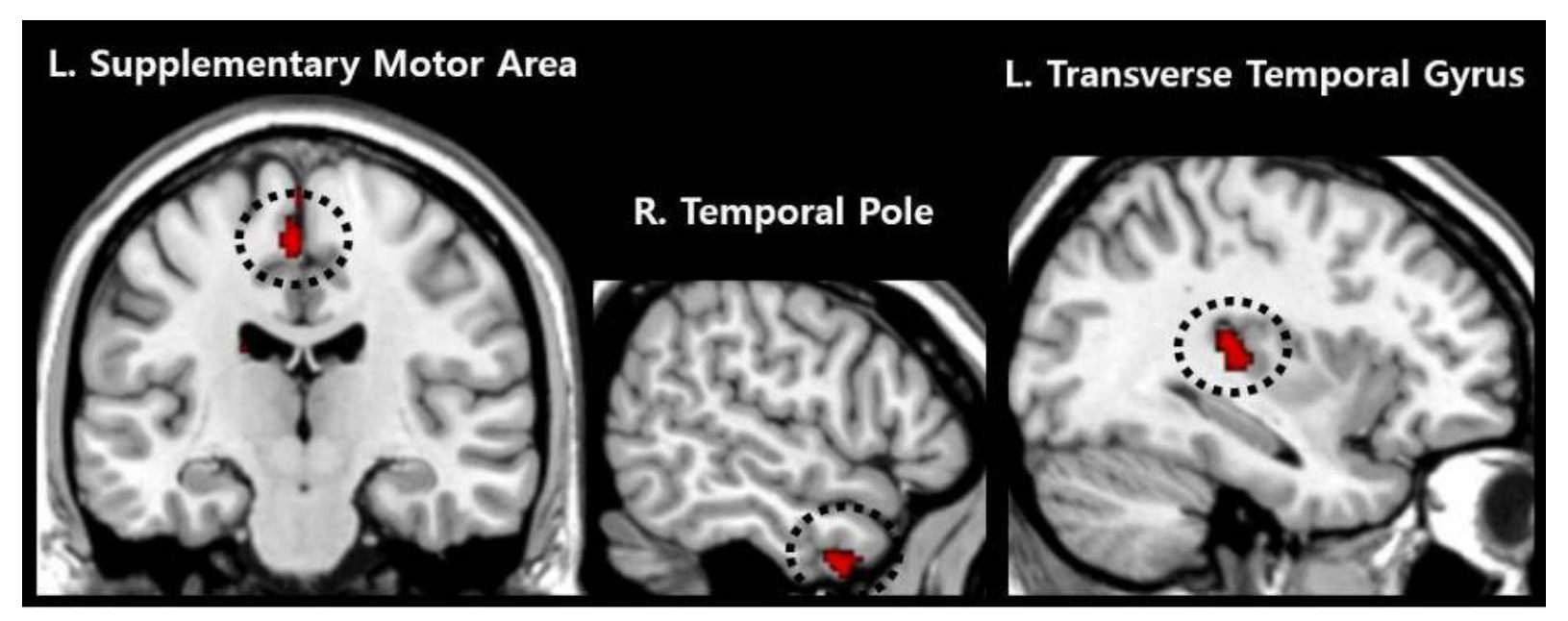

Brain regions with decreased volume in postoperatively delirious patients compared with non-delirious patients controlling for cognitive level.

\begin{tabular}{lccccc}
\hline Brain region (Brodmann area) & \multirow{2}{*}{ Nvox } & Zmax & \multicolumn{3}{c}{ MNI coordinates } \\
\cline { 4 - 6 } & & & $\mathrm{x}$ & $\mathrm{y}$ & $\mathrm{z}$ \\
\hline L. Supplementary motor area (6) & 223 & 3.95 & -2 & -24 & 66 \\
R. Precuneus (7) & 148 & 3.56 & 11 & -36 & 39 \\
R. Temporal pole (21) & 297 & 3.86 & 56 & 5 & -36 \\
L. Transverse temporal gyrus (41) & 165 & 3.79 & -35 & -27 & 12 \\
L. Caudate nucleus & 748 & 4.24 & -12 & 8 & 14 \\
\hline
\end{tabular}

\section{References:}

1. Cole MG, Ciampi A, Belzile E, Zhong L. Persistent delirium in older hospital patients: a systematic review of frequency and prognosis. Age Ageing 2009;38:19-26.

2. Saczynski JS, Marcantonio ER, Quach L, Fong TG, Gross A, Inouye SK, et al. Cognitive trajectories after postoperative delirium. N Engl J Med 2012;367:30-39.

3. Kyeong S, Shin JE, Yang KH, Lee WS, Chung TS, Kim JJ. Neural predisposing factors of postoperative delirium in elderly patients with femoral neck fracture. Scientific reports 2018;8:7602 